\title{
Miscellany
}

\section{Society for Existential Analysis}

The Society was founded in July 1988; its members are philosophers, psychoanalysts, psychotherapists, counsellors and students who are interested in exploring what a phenomenological-existential approach can offer them. It provides a forum for an exchange of ideas and views in the form of meetings, conferences, a Newsletter and a Bulletin, and seeks to develop and expand an existential perspective on psychotherapy and counselling. At present the Society is open to anyone who wants to join, although later on different categories of membership might be created (especially with a view to set up a referral system). Further information: Mr D. Williamson, Society for Existential Analysis, 20 Beachborough Road, Bromley, Kent BR1 5RL (telephone 01-658 7303).

\section{South Western Division Prize}

This prize is awarded for the best piece of original work submitted during the calendar year by a trainee. There is an award of $£ 100$ and the winner is invited to present his or her winning paper at a meeting of the South Western Division. Dr Erica Jones, a lecturer in mental health from the University of Bristol, is the 1988 winner. Dr Jones will be invited to present her paper entitled 'The Effect of Inter-hospital Transfer on Long-stay Psychiatric Patients' at the meeting of the South Western Division to be held at Southmead Hospital, Bristol, on 27 October 1989.

\section{New publication}

Mental Health in Primary Care: A New Perspective, a report from Good Practices in Mental Health, presents a new approach to community mental health care based on the network of primary care services of the NHS and says that GPs look likely to be increasingly important in determining the care received by people with mental health problems. A supplementary booklet, Examples of Professional Attachments, sets out the model in detail for individual professions. Further details of these and other publications are available from: GPMH, 380-384 Harrow Road, London W9 2HU (telephone 01-289 3060/289 2034).

\section{Information systems}

Plymouth Health Authority and Protechnic Computers are to develop the first resource management information system for community psychiatric services. The 26 terminal system will be designed to ensure continuity of care for all psychiatric patients during and after a major shift in emphasis from hospital to community-based care. Protechnic Computers are basing the system on their existing Mental Health Connection information system for psychiatry which gives health care professionals instant access to a range of patient information from demographic details to extensive clinical and managerial information. Further details can be obtained from Andy Shuttleworth, Protechnic Computers, 264 Newmarket Road, Cambridge CB5 HJR or Martin Cusack, Director of Information, Plymouth Health Authority, Derriford Business Park, Plymouth PL6 5XN.

Vuman, a company wholly owned by the university of Manchester and which was incorporated in 1981 to market products developed as a result of research in various departments of the university, has announced the release of Vuman Clinicbase. Developed by the Department of Medical Computation, it is a new type of package which exploits the information locked in clinical letters. It combines a database manager with a word processor to simplyfy the management of patient records and correspondence for use in hospital departments and medical centres. Further details can be obtained from Philippa Moss (telephone 061-226 8311).

\section{Cumulative indexes}

The Journal Editorial Committee is considering the publication of cumulative indexes for the British

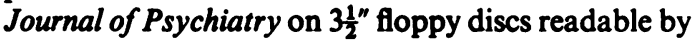
an IBM-compatible PC. As it is not known how much demand there will be for such an index, it would be appreciated if Members who are interested would write to Elaine Millen, Psychiatric Bulletin. 